\title{
Distribuição do sistema radicular de porta-enxertos sob laranjeira 'Folha Murcha' em clima subtropical
}

\section{Root system distribution of rootstocks under 'Folha Murcha' orange plant scion in subtropical climate}

\author{
Paulo Vicente Contador Zaccheo ${ }^{1 *}$; Carmen Silvia Vieira Janeiro Neves²; \\ Neusa Maria Colauto Stenzel ${ }^{3}$; Ricardo Shigueru Okumura ${ }^{4}$
}

\section{Resumo}

Objetivou-se estudar a distribuição do sistema radicular dos limoeiros 'Cravo' (Citrus limonia Osbeck) e 'Rugoso da África' (Citrus jambluri Lush.), tangerineira 'Cleópatra' (Citrus reshni Hort ex Tan.) e 'Trifoliata' (Poncirus trifoliata (L.) Ralf.), sob a laranjeira 'Folha Murcha' em clima subtropical. As amostragens foram realizadas, pelo método do trado, paralelamente à linha de plantio (entre plantas) a 0,$5 ; 1,0 ; 1,5$ e $2,0 \mathrm{~m}$ de distância do tronco e perpendicularmente à linha de plantio (entrelinhas) a 0,$5 ; 1,0 ; 1,5 ; 2,0 ; 2,5 ; 3,0$ e $3,5 \mathrm{~m}$ de distância do tronco. Essas amostras foram estratificadas em 0 0,$1 ; 0,1-0,2 ; 0,2-0,4 ; 0,4-0,6 \mathrm{~m}$ de profundidade. Foram determinadas: massa seca, profundidade e distâncias efetivas do sistema radicular das plantas. O delineamento experimental utilizado foi o de blocos ao acaso, com quatro tratamentos e quatro repetições, com uma planta por parcela. A tangerineira 'Cleópatra' apresentou maior massa total de raízes a 2,0, 2,5 e 3,0 m de distância do tronco na entrelinha e nas camadas superficiais dos seguintes locais de amostragem: 0,5 e 1,0 m de distância do tronco no sentido da linha e 1,5 e 2,0 m de distância do tronco no sentido da entrelinha. O limoeiro 'Rugoso da África' apresentou maior profundidade efetiva das raízes na linha de plantio.

Palavras-chave: Citrus sinensis, raízes, método do trado

\begin{abstract}
The aim was to study the distribution of the root system of Rangpur lime (Citrus limonia Osbeck), Rough lemon (Citrus jambluri Lush.), Cleopatra mandarin (Citrus reshni Hort ex Tan.) and Trifoliata (Poncirus trifoliata (L.) Ralf.), under 'Folha Murcha' orange plant scion in subtropical climate, using the auger method. The samples were taken parallel to the line of planting (row) $0.5 ; 1.0 ; 1.5$ and $2.0 \mathrm{~m}$ away from the trunk and perpendicular to the line of planting (inter-row) $0.5 ; 1.0 ; 1.5 ; 2.0 ; 2.5 ; 3.0$ and $3.5 \mathrm{~m}$ away from the trunk. These samples were stratified into $0-0.1 ; 0.1-0.2 ; 0.2-0.4 ; 0.4-0.6 \mathrm{~m}$ deep. Dry mass, effective depth and effective distance of the root system of plants were determined. Randomized blocks design was used with four treatments and four replications, with one plant for each plot. Cleopatra mandarin plants had the highest total mass of roots 2.0; 2.5 and 3.0 m away from the trunck in inter-row, and in superficial layers of the following sampling sites: 0.5 and $1.0 \mathrm{~m}$ away from the trunk towards row and 1.5 e $2.0 \mathrm{~m}$ away from the trunck towards inter-row. Rough lemon plants showed greater effective depth of the roots in the rows than the other rootstocks.
\end{abstract}

Key words: Citrus sinensis, roots, auger method

\footnotetext{
${ }^{1}$ Eng $^{\mathrm{o}}$ Agr $^{\mathrm{o}}$, Msc. Doutorando do PPG em Agronomia da Universidade Estadual de Londrina, UEL, Londrina, PR. E-mail: pvczaccheo@yahoo.com.br

${ }^{2}$ Eng $^{\mathrm{a}}$ Agr $^{\mathrm{a}}$, Prof $^{\mathrm{a}}$ Dr $^{\mathrm{a}}$. do Dept ${ }^{\mathrm{o}}$ de Agronomia, UEL, Londrina, PR. E-mail: csvjneve@uel.br

${ }^{3}$ Eng $^{\mathrm{a}}$ Agr $^{\mathrm{a}}$, Dr ${ }^{\mathrm{a}}$. Pesquisadora do Instituto Agronômico do Paraná, IAPAR, Londrina, PR. E-mail: nstenzel@iapar.br

${ }^{4}$ Eng $^{\mathrm{o}} \mathrm{Agr}^{\mathrm{o}}$, MSc. Doutorando do PPG em Agronomia da Universidade Estadual de Maringá, UEM, Maringá, PR. E-mail: ricardo_ okumura@hotmail.com

* Autor para correspondência
} 


\section{Introdução}

A laranja é a principal fruta produzida no Estado do Paraná, com área de aproximadamente 21.000 ha, tendo a região noroeste como o principal pólo produtor (IBGE, 2012). As variedades mais plantadas são Pêra, Folha Murcha e Valência, cuja produção é destinada à elaboração de suco concentrado congelado e para consumo in natura (STENZEL et al., 2005a). A 'Folha Murcha' é uma seleção da 'Valência', originária do Estado do Rio de Janeiro, e caracterizada pelo enrolamento permanente das folhas, maturação tardia dos frutos, porte mediano da copa e resistência ao cancro cítrico (STUCHI; DONADIO, 2000).

$\mathrm{Na}$ citricultura, os porta-enxertos são utilizados por propiciar boas características agronômicas às variedades-copa. Pompeu Júnior (1991) destaca que os porta-enxertos, em geral, induzem à copa alterações no seu crescimento, precocidade de produção, época de maturação e peso dos frutos, permanência dos frutos na planta, capacidade de absorção, síntese e utilização de nutrientes, tolerância à salinidade, resistência à seca e ao frio, resistência ou tolerância a moléstias e pragas, além de outros.

Dentre os porta-enxertos, o limoeiro 'Cravo' é o mais utilizado no Brasil e no Paraná pela capacidade de induzir tolerância à seca às copas nele enxertadas, tolerância ao vírus da tristeza dos citros e elevado vigor vegetativo (STENZEL et al., 2005b). Contudo, apresenta suscetibilidade à gomose, ao declínio e à morte súbita (MÜLLER et al., 2002), o que pode aumentar os riscos fitossanitários e comprometer a produção (STUCHI et al, 2008).

Assim, vários trabalhos têm sido desenvolvidos visando diversificar os porta-enxertos e determinar os mais adequados para as diferentes variedadescopa, nas diversas regiões produtoras do Brasil (STENZEL et al., 2005c; PRUDENTE; SILVA; SOBRINHO, 2004; STENZEL; NEVES, 2004; LEDO et al., 1999). No Noroeste do Paraná, o limoeiro 'Rugoso da África', a tangerineira 'Cleópatra' e o 'Trifoliata' têm se mostrado promissores quando combinados com a 'Folha Murcha' por induzirem maior produção acumulada, volume de copa e teor de sólidos solúveis totais, respectivamente (STENZEL et al., 2005b).

As características avaliadas com maior freqüência nos porta-enxertos são a influência sobre o crescimento vegetativo, a produtividade e a qualidade dos frutos das variedades-copa. Existem poucos trabalhos a respeito do desenvolvimento e distribuição do sistema radicular de plantas cítricas enxertadas sobre diferentes porta-enxertos. Estudos com esse enfoque se fazem necessários pela importância das raízes na sustentação da planta e na absorção de água e nutrientes e também pela sua importância em relação à determinação da localização de adubos e irrigação (COELHO et al., 2002; BONI et al., 2008). Um correto dimensionamento do sistema radicular auxilia na escolha de locais apropriados para a instalação de instrumentos, como o tensiômetro, visando ao manejo de irrigação, ou, ainda, em sistemas de irrigação localizada, permite fixar a distância adequada a partir do tronco onde deverá ser aplicada a água bem como a profundidade que a mesma deve atingir (OLIVEIRA; VIEIRA; SOUZA, 1998).

Considerando a escassez de trabalhos focados na avaliação das raízes de porta-enxertos, o trabalho teve como objetivo avaliar a distribuição do sistema radicular de quatro porta-enxertos sob copa de laranjeira 'Folha Murcha' em clima subtropical.

\section{Material e Métodos}

O experimento foi conduzido na Estação Experimental do Instituto Agronômico do Paraná (IAPAR), no município de Paranavaí-PR (23도' $\mathrm{S}, 52^{\circ}$ 26'W; altitude $480 \mathrm{~m}$ ). O solo da área experimental é um ARGISSOLO VERMELHO Distrófico de textura arenosa (BHERING, 2007). O clima está classificado segundo Köppen como Cfa, subtropical úmido, com precipitação média anual de $1.500 \mathrm{~mm}$, 
principalmente na primavera e verão, temperatura média anual de $22,5^{\circ} \mathrm{C}$, evapotranspiração anual de $1400 \mathrm{~mm}$ e umidade relativa média anual de $70 \%$ (CAVIGLIONE et al., 2000).

O pomar foi implantado em dezembro de 1988 com espaçamento de 7,0 x 4,0 m, conduzido sem irrigação e manejado conforme recomendações técnicas para o cultivo na região (IAPAR, 1992). Os porta-enxertos foram propagados por meio de sementes e enxertados com borbulhas procedentes de uma única planta de laranjeira 'Folha Murcha' [Citrus sinensis (L.) Osbeck] da coleção do IAPAR.

O delineamento experimental utilizado foi o de blocos ao acaso, com quatro tratamentos (portaenxertos) e quatro repetições, com uma planta por parcela. Os tratamentos foram: limoeiros 'Cravo' (Citrus limonia Osbeck) e 'Rugoso da África' (Citrus jambluri Lush.), tangerineira 'Cleópatra' (Citrus reshni Hort ex Tan.) e 'Trifoliata' (Poncirus trifoliata (L.) Ralf.).

Para avaliar a distribuição do sistema radicular foi utilizado um trado cilíndrico tipo caneca com 0,074m de diâmetro (BÖHM, 1979). A avaliação foi realizada no mês de julho de 2009, quando as plantas estavam com aproximadamente 20 anos de idade. As amostras foram coletadas paralelamente à linha de plantio (entre plantas) a 0,$5 ; 1,0 ; 1,5 \mathrm{e}$ 2,0 $\mathrm{m}$ de distância do tronco e perpendicularmente à linha de plantio (entre linhas) a 0,$5 ; 1,0 ; 1,5 ; 2,0$; 2,5; 3,0 e 3,5 m de distância do tronco. Cada ponto de amostragem foi estratificado em $0-0,1 ; 0,1-$ 0,$2 ; 0,2-0,4 ; 0,4-0,6 \mathrm{~m}$ de profundidade, uma vez que a maior parte da atividade radicular das plantas cítricas se concentra até essa profundidade (CRUZ et al., 2005).

O solo retirado foi acondicionado em sacos plásticos que foram levados ao laboratório, onde permaneceram armazenados em freezer horizontal $\mathrm{a}-15{ }^{\circ} \mathrm{C}$ para conservação das raízes até que fossem separadas. A separação foi feita através da lavagem das amostras em água corrente com o auxílio de peneiras com malha de $500 \mu \mathrm{m}$. As raízes retidas nas peneiras foram separadas de outros materiais orgânicos com o auxílio de pinças, envolvidas em papel toalha e acondicionadas em sacos de papel. Em seguida, esse material foi levado à estufa de ventilação forçada à temperatura de $70^{\circ} \mathrm{C}$ por 48 horas. $\mathrm{Na}$ seqüência, após a secagem, as raízes de outras espécies e as grossas ( $>2 \mathrm{~mm}$ ) foram separadas, pesando-se as restantes, consideradas ativas, em balança de precisão para determinação da massa seca.

Após a determinação da massa seca foram calculados os valores de massa de raízes por profundidade, por local de amostragem e total. A partir da distribuição percentual do sistema radicular por profundidade e por distância da planta, foram estimadas a profundidade e distância efetivas, que representam o limite até onde se encontram $80 \%$ das raízes (KLAR, 1991).

Os dados foram submetidos à análise de variância e quando significativo, as médias foram comparadas pelo teste Tukey a 5\% de significância.

\section{Resultados e Discussão}

Não houve diferença significativa entre os portaenxertos na comparação da massa seca total de raízes na linha e na entrelinha de plantio (Tabelas 1 e 2). Porém, na linha de plantio, foram observadas diferenças significativas em três locais (Tabela 1): a $0,5 \mathrm{~m}$ de distância do tronco da planta, na profundidade de $0-0,1 \mathrm{~m}$, a 'Cleópatra' apresentou maior massa seca de raízes do que os demais portaenxertos; no intervalo de $0,2-0,4 \mathrm{~m}$ do mesmo local de amostragem, a 'Cleópatra' superou o 'Cravo' e o 'Trifoliata'; e, a 1,0 m do tronco, na profundidade de $0-0,10 \mathrm{~m}$, a massa seca de raízes da 'Cleópatra' foi significativamente maior em relação à do 'Cravo', sem diferir estatisticamente dos demais porta-enxertos. 
Tabela 1. Massa seca de raízes de porta-enxertos sob copa de laranjeira 'Folha Murcha', distribuídas na linha de plantio. Paranavaí-PR, 2009.

\begin{tabular}{|c|c|c|c|c|c|c|c|}
\hline \multicolumn{8}{|c|}{ Porta-enxertos } \\
\hline & & 'Cravo’' & $\begin{array}{l}\text { 'Rugoso da } \\
\text { África' }\end{array}$ & 'Cleópatra' & 'Trifoliata' & $\mathrm{CV}$ & DMS \\
\hline $\begin{array}{l}\text { Local } \\
\text { Linha }\end{array}$ & $\begin{array}{l}\text { Profund. } \\
\quad(\mathrm{m})\end{array}$ & \multicolumn{4}{|c|}{$\begin{array}{c}\text { Massa seca } \\
(\mathrm{mg})\end{array}$} & $(\%)$ & $(\mathrm{mg})$ \\
\hline \multirow{4}{*}{$0,5 \mathrm{~m}$} & $0-0,1$ & $242 b^{*}$ & $676 \mathrm{~b}$ & $2.210 \mathrm{a}$ & $823 \mathrm{~b}$ & 58,3 & 1247 \\
\hline & $0,1-0,2$ & $1.559 \mathrm{a}$ & $2.369 \mathrm{a}$ & $2.453 \mathrm{a}$ & $314 \mathrm{a}$ & 156,1 & 5995 \\
\hline & $0,2-0,4$ & $33 \mathrm{~b}$ & $349 a b$ & $594 \mathrm{a}$ & $32 \mathrm{~b}$ & 56,1 & 353 \\
\hline & $0,4-0,6$ & $305 \mathrm{a}$ & $5.714 \mathrm{a}$ & $463 \mathrm{a}$ & $74 \mathrm{a}$ & 287,8 & 10421 \\
\hline Total & & $2.132 \mathrm{a}$ & $8.517 \mathrm{a}$ & $5.168 \mathrm{a}$ & $1.244 \mathrm{a}$ & 131,9 & 12431 \\
\hline \multirow{4}{*}{$1,0 \mathrm{~m}$} & $0-0,1$ & $79 \mathrm{~b}$ & $501 \mathrm{ab}$ & $1.121 \mathrm{a}$ & $448 \mathrm{ab}$ & 82,6 & 981 \\
\hline & $0,1-0,2$ & $221 \mathrm{a}$ & $1.124 \mathrm{a}$ & $1.397 \mathrm{a}$ & $68 \mathrm{a}$ & 96,5 & 1757 \\
\hline & $0,2-0,4$ & $222 \mathrm{a}$ & $298 \mathrm{a}$ & $282 \mathrm{a}$ & $184 \mathrm{a}$ & 140,9 & 873 \\
\hline & $0,4-0,6$ & $5 \mathrm{a}$ & $2.956 \mathrm{a}$ & $2.761 \mathrm{a}$ & $422 \mathrm{a}$ & 204,2 & 6931 \\
\hline Total & & $473 \mathrm{a}$ & $4.524 \mathrm{a}$ & $5.212 \mathrm{a}$ & $1.106 \mathrm{a}$ & 125,9 & 7866 \\
\hline \multirow{4}{*}{$1,5 \mathrm{~m}$} & $0-0,1$ & $303 \mathrm{a}$ & $527 \mathrm{a}$ & $505 \mathrm{a}$ & $562 \mathrm{a}$ & 86,6 & 993 \\
\hline & $0,1-0,2$ & $1.233 \mathrm{a}$ & $206 \mathrm{a}$ & $2.733 \mathrm{a}$ & $131 \mathrm{a}$ & 109,7 & 2936 \\
\hline & $0,2-0,4$ & $272 \mathrm{a}$ & $1.017 \mathrm{a}$ & $2.449 \mathrm{a}$ & $26 \mathrm{a}$ & 185,3 & 5200 \\
\hline & $0,4-0,6$ & $324 \mathrm{a}$ & $1.978 \mathrm{a}$ & $190 \mathrm{a}$ & $15 \mathrm{a}$ & 227,5 & 3152 \\
\hline Total & & $2.057 \mathrm{a}$ & $3.678 \mathrm{a}$ & $5.878 \mathrm{a}$ & $722 \mathrm{a}$ & 95,1 & 6477 \\
\hline \multirow{4}{*}{$2,0 \mathrm{~m}$} & $0-0,1$ & $426 \mathrm{a}$ & $292 \mathrm{a}$ & $616 a$ & $300 \mathrm{a}$ & 79,5 & 809 \\
\hline & $0,1-0,2$ & $710 \mathrm{a}$ & $1.189 \mathrm{a}$ & $680 \mathrm{a}$ & $1.043 \mathrm{a}$ & 119,1 & 2382 \\
\hline & $0,2-0,4$ & $251 \mathrm{a}$ & $235 \mathrm{a}$ & $206 \mathrm{a}$ & $127 \mathrm{a}$ & 129,0 & 618 \\
\hline & $0,4-0,6$ & $165 \mathrm{a}$ & $508 \mathrm{a}$ & $144 \mathrm{a}$ & $190 \mathrm{a}$ & 147,1 & 900 \\
\hline Total & & $1.553 \mathrm{a}$ & $2.093 \mathrm{a}$ & $1.456 \mathrm{a}$ & $1.662 \mathrm{a}$ & 72,9 & 2723 \\
\hline $\begin{array}{l}\text { Total } \\
\text { geral }\end{array}$ & & $6.215 \mathrm{a}$ & $18.812 \mathrm{a}$ & $17.716 \mathrm{a}$ & $4.735 \mathrm{a}$ & 59,9 & 15726 \\
\hline
\end{tabular}

*Médias seguidas da mesma letra na linha não diferem estatisticamente entre si, no nível de 5\% de probabilidade pelo teste Tukey. Fonte: Elaboração dos autores.

Os dados referentes à distribuição das raízes em direção à entrelinha apresentaram diferenças significativas em dois locais (Tabela 2): a 1,5 m do tronco, no intervalo de $0-0,1$ de profundidade, a massa seca de raízes da 'Cleópatra' foi significativamente maior quando comparada à 'Cravo', não diferindo do 'Rugoso da África' e do 'Trifoliata'; e a 2,0 $\mathrm{m}$ do tronco, nos intervalos de $0-0,1$ e $0,1-0,2 \mathrm{~m}$ de profundidade, a massa seca de raízes observada na 'Cleópatra' foi também superior, diferindo significativamente do 'Trifoliata' na primeira profundidade e de todos os tratamentos na profundidade subsequente.
Quando analisado o total de massa seca de raízes por local de amostragem no sentido da entrelinha verificou-se que a 'Cleópatra' superou os demais porta-enxertos a 2,0 m, o 'Cravo' e o 'Trifoliata' a 2,5 m e o 'Trofoliata' a 3,0 $\mathrm{m}$ de distância do tronco (Tabela 2). Esse maior desenvolvimento radicular pode explicar a influência exercida pela 'Cleópatra' no crescimento e desenvolvimento das plantas. Stenzel et al. (2003), em Latossolo Vermelho distrófico, em clima subtropical, avaliando o comportamento da tangerineira 'Poncã' sobre sete porta-enxertos, verificaram que a 'Cleópatra' e o 'Rugoso da África' induziram maior altura e maior volume de copa às plantas. Cintra, Libardi e Jorge 
(1999) avaliaram a distribuição do sistema radicular de cinco porta-enxertos de citros em solo de tabuleiro costeiro em Sergipe e constataram que a 'Cleópatra' também se destacou dos demais porta-enxertos estudados, apresentando maior densidade de raízes, principalmente nas camadas mais superficiais.

Tabela 2. Massa seca de raízes de porta-enxertos sob copa de laranjeira 'Folha Murcha', distribuídas na entrelinha. Paranavaí-PR, 2009.

\begin{tabular}{|c|c|c|c|c|c|c|c|}
\hline \multicolumn{8}{|c|}{ Porta-enxertos } \\
\hline & & 'Cravo’' & $\begin{array}{c}\text { 'Rugoso da } \\
\text { África' }\end{array}$ & 'Cleópatra' & 'Trifoliata' & $\mathrm{CV}$ & DMS \\
\hline $\begin{array}{c}\text { Local } \\
\text { Entrelinha }\end{array}$ & $\begin{array}{l}\text { Profund. } \\
\text { (m) }\end{array}$ & \multicolumn{6}{|c|}{ Massa seca } \\
\hline \multirow{4}{*}{$0,5 \mathrm{~m}$} & $0-0,1$ & $720 a^{*}$ & $1.204 \mathrm{a}$ & $1.170 \mathrm{a}$ & $708 \mathrm{a}$ & 110,7 & 2324 \\
\hline & $0,1-0,2$ & $1.650 \mathrm{a}$ & $427 \mathrm{a}$ & $267 \mathrm{a}$ & $100 \mathrm{a}$ & 257,6 & 3478 \\
\hline & $0,2-0,4$ & $2.004 \mathrm{a}$ & $4.518 \mathrm{a}$ & 326 a & $302 \mathrm{a}$ & 233,7 & 9228 \\
\hline & $0,4-0,6$ & $63 \mathrm{a}$ & $1.331 \mathrm{a}$ & $190 \mathrm{a}$ & $156 \mathrm{a}$ & 205,1 & 1971 \\
\hline Total & & $4.438 \mathrm{a}$ & $7.481 \mathrm{a}$ & $1.953 \mathrm{a}$ & $1.267 \mathrm{a}$ & 104,2 & 8716 \\
\hline \multirow{4}{*}{$1,0 \mathrm{~m}$} & $0-0,1$ & $380 \mathrm{a}$ & $64 \mathrm{a}$ & $1.725 \mathrm{a}$ & $781 \mathrm{a}$ & 153,9 & 2765 \\
\hline & $0,1-0,2$ & $3.507 \mathrm{a}$ & $52 \mathrm{a}$ & $2.549 \mathrm{a}$ & $237 \mathrm{a}$ & 268,3 & 9636 \\
\hline & $0,2-0,4$ & $12 \mathrm{a}$ & $235 \mathrm{a}$ & $99 \mathrm{a}$ & $420 \mathrm{a}$ & 184,1 & 886 \\
\hline & $0,4-0,6$ & $812 \mathrm{a}$ & $143 \mathrm{a}$ & $1.265 \mathrm{a}$ & $167 \mathrm{a}$ & 230,1 & 2998 \\
\hline Total & & $4.615 \mathrm{a}$ & $495 \mathrm{a}$ & $4.685 \mathrm{a}$ & $1.606 \mathrm{a}$ & 146,3 & 4351 \\
\hline \multirow{4}{*}{$1,5 \mathrm{~m}$} & $0-0,1$ & $100 \mathrm{~b}$ & $272 \mathrm{ab}$ & $793 \mathrm{a}$ & $567 \mathrm{ab}$ & 66,7 & 638 \\
\hline & $0,1-0,2$ & $203 \mathrm{a}$ & $282 \mathrm{a}$ & $1.742 \mathrm{a}$ & $835 \mathrm{a}$ & 182,5 & 3374 \\
\hline & $0,2-0,4$ & $141 \mathrm{a}$ & $491 \mathrm{a}$ & $143 \mathrm{a}$ & $300 \mathrm{a}$ & 158,5 & 942 \\
\hline & $0,4-0,6$ & $423 \mathrm{a}$ & $106 \mathrm{a}$ & $208 \mathrm{a}$ & $128 \mathrm{a}$ & 196,3 & 938 \\
\hline Total & & $867 \mathrm{a}$ & $1.082 \mathrm{a}$ & $2.452 \mathrm{a}$ & $1.830 \mathrm{a}$ & 102,4 & 3527 \\
\hline \multirow{4}{*}{$2,0 \mathrm{~m}$} & $0-0,1$ & $233 \mathrm{ab}$ & $61 \mathrm{ab}$ & $651 \mathrm{a}$ & $27 \mathrm{~b}$ & 90,8 & 596 \\
\hline & $0,1-0,2$ & $90 \mathrm{~b}$ & $54 \mathrm{~b}$ & $1.716 \mathrm{a}$ & $109 \mathrm{~b}$ & 92,0 & 1000 \\
\hline & $0,2-0,4$ & $7 \mathrm{a}$ & $152 \mathrm{a}$ & $211 \mathrm{a}$ & $96 \mathrm{a}$ & 172,9 & 507 \\
\hline & $0,4-0,6$ & 59 a & $283 a$ & 319 a & $77 \mathrm{a}$ & 167,5 & 683 \\
\hline Total & & $331 \mathrm{~b}$ & $513 \mathrm{~b}$ & $2.898 \mathrm{a}$ & $279 \mathrm{~b}$ & 61,0 & 1355 \\
\hline \multirow{4}{*}{$2,5 \mathrm{~m}$} & $0-0,1$ & $274 \mathrm{a}$ & $259 a$ & $455 \mathrm{a}$ & $87 \mathrm{a}$ & 105,9 & 629 \\
\hline & $0,1-0,2$ & $68 \mathrm{a}$ & $190 \mathrm{a}$ & 822 a & $143 \mathrm{a}$ & 255,8 & 1729 \\
\hline & $0,2-0,4$ & $230 \mathrm{a}$ & $545 \mathrm{a}$ & $951 \mathrm{a}$ & $128 \mathrm{a}$ & 114,5 & 1173 \\
\hline & $0,4-0,6$ & $155 \mathrm{a}$ & $315 \mathrm{a}$ & $1.575 \mathrm{a}$ & $178 \mathrm{a}$ & 122,8 & 1687 \\
\hline Total & & $689 \mathrm{~b}$ & $1.309 \mathrm{ab}$ & $3.804 \mathrm{a}$ & $537 \mathrm{~b}$ & 82,8 & 2902 \\
\hline \multirow{4}{*}{$3,0 \mathrm{~m}$} & $0-0,1$ & $117 \mathrm{a}$ & $421 \mathrm{a}$ & $467 \mathrm{a}$ & $0 \mathrm{a}$ & 90,7 & 574 \\
\hline & $0,1-0,2$ & $162 \mathrm{a}$ & $238 \mathrm{a}$ & $400 \mathrm{a}$ & $107 \mathrm{a}$ & 105,2 & 527 \\
\hline & $0,2-0,4$ & $185 \mathrm{a}$ & $12 \mathrm{a}$ & 333 a & $74 \mathrm{a}$ & 143,4 & 529 \\
\hline & $0,4-0,6$ & $80 \mathrm{a}$ & $201 \mathrm{a}$ & $124 \mathrm{a}$ & $32 \mathrm{a}$ & 95,7 & 231 \\
\hline Total & & $545 \mathrm{ab}$ & $873 \mathrm{ab}$ & $1.325 \mathrm{a}$ & $196 \mathrm{~b}$ & 55,7 & 905 \\
\hline \multirow{4}{*}{$3,5 \mathrm{~m}$} & $0-0,1$ & $69 \mathrm{a}$ & $207 \mathrm{a}$ & $92 \mathrm{a}$ & $0 \mathrm{a}$ & 132,6 & 270 \\
\hline & $0,1-0,2$ & $7 \mathrm{a}$ & $92 \mathrm{a}$ & $80 \mathrm{a}$ & $32 \mathrm{a}$ & 150,6 & 179 \\
\hline & $0,2-0,4$ & 79 a & $125 \mathrm{a}$ & $130 \mathrm{a}$ & $120 \mathrm{a}$ & 90,3 & 226 \\
\hline & $0,4-0,6$ & $174 \mathrm{a}$ & $116 \mathrm{a}$ & $235 \mathrm{a}$ & $82 \mathrm{a}$ & 83,3 & 280 \\
\hline Total & & $330 \mathrm{a}$ & $519 \mathrm{a}$ & $538 \mathrm{a}$ & $234 \mathrm{a}$ & 65,3 & 584 \\
\hline Total geral & & $11.818 \mathrm{a}$ & $12.274 \mathrm{a}$ & $17.658 \mathrm{a}$ & $5.952 \mathrm{a}$ & 57,6 & 15177 \\
\hline
\end{tabular}

*Médias seguidas da mesma letra na linha não diferem estatisticamente entre si, no nível de 5\% de probabilidade pelo teste Tukey.

Fonte: Elaboração dos autores. 
Estes resultados mostram que o vigor do sistema radicular da 'Cleópatra' prevaleceu sobre os demais porta-enxertos independentemente do tipo de solo e das condições climáticas, pois nas três condições avaliadas esse porta-enxerto se destacou, tanto no solo arenoso do presente trabalho como no solo muito argiloso do trabalho de Stenzel et al. (2003) conduzido também em clima subtropical, quanto no solo de tabuleiro costeiro, que apresenta uma camada coesa superficial e fica situado em uma região de clima quente (Af) com precipitação média de 1200 mm (CINTRA; LIBARDI; JORGE, 1999).

Os elevados valores de coeficiente de variação observados no presente trabalho (Tabelas 1 e 2) são explicados pela acentuada variabilidade espacial encontrada, sendo isso uma característica recorrente nos estudos da atividade e da distribuição do sistema radicular de plantas (MACHADO; COELHO, 2000).

Na comparação das profundidades e distâncias efetivas entre os porta-enxertos foram verificadas diferenças significativas somente nos valores referentes à profundidade efetiva na linha de plantio (Tabela 3). O 'Rugoso da África' apresentou maior profundidade efetiva na linha de plantio em relação ao 'Trifoliata', porém não diferiu estatisticamente da 'Cleópatra' e do 'Cravo'. O maior aprofundamento observado no 'Rugoso da África' pode ser decisivo para a produção de frutos quando ocorrer estresse hídrico, pois, nessas condições, essa característica permite a exploração de maior volume do solo, justamente nas camadas onde ainda possa existir água disponível (MAZZA et al., 1994).

Tabela 3. Profundidades (PE) e distâncias (DE) efetivas do sistema radicular de porta-enxertos sob copa de laranjeira 'Folha Murcha' na linha e entrelinha de plantio. Paranavaí-PR, 2009.

\begin{tabular}{|c|c|c|c|c|c|c|}
\hline & \multicolumn{4}{|c|}{ Porta-enxertos } & \multirow[b]{2}{*}{ CV $(\%)$} & \multirow[b]{2}{*}{$\operatorname{DMS}(\mathrm{m})$} \\
\hline & 'Cravo' & $\begin{array}{c}\text { 'Rugoso da } \\
\text { África' }\end{array}$ & 'Cleópatra' & 'Trifoliata' & & \\
\hline \multicolumn{7}{|c|}{ Linha } \\
\hline $\mathrm{PE}(\mathrm{m})$ & $0,27 a b^{*}$ & $0,53 \mathrm{a}$ & $0,34 \mathrm{ab}$ & $0,23 \mathrm{~b}$ & 36,85 & 0,27 \\
\hline $\mathrm{DE}(\mathrm{m})$ & $1,58 \mathrm{a}$ & $1,07 \mathrm{a}$ & $1,29 \mathrm{a}$ & $1,64 \mathrm{a}$ & 24,04 & 0,74 \\
\hline \multicolumn{7}{|c|}{ Entrelinha } \\
\hline $\mathrm{PE}(\mathrm{m})$ & $0,36 \mathrm{a}$ & $0,44 \mathrm{a}$ & $0,36 \mathrm{a}$ & $0,33 \mathrm{a}$ & 18,68 & 0,15 \\
\hline $\mathrm{DE}(\mathrm{m})$ & $1,65 \mathrm{a}$ & $1,90 \mathrm{a}$ & $2,28 \mathrm{a}$ & $1,55 \mathrm{a}$ & 29,23 & 1,19 \\
\hline $\begin{array}{l}\text { Raio médio } \\
\text { da copa }(\mathrm{m})\end{array}$ & 2,05 & 2,49 & 2,39 & 1,59 & & \\
\hline
\end{tabular}

*Médias seguidas da mesma letra na linha não diferem estatisticamente entre si, no nível de 5\% de probabilidade pelo teste Tukey. Fonte: Elaboração dos autores.

A profundidade efetiva do 'Cravo' foi $0,27 \mathrm{~m}$ na linha de plantio e $0,36 \mathrm{~m}$ na entrelinha (Tabela 3). Abreu e Salviano (2007), estudando o sistema radicular de diferentes porta-enxertos sob limeira ácida 'Tahiti', em um Neossolo Quartzarênico, no Estado do Piauí, observaram que nos primeiros $0,4 \mathrm{~m}$ de profundidade encontrava-se $91,2 \%$ do comprimento radicular do 'Cravo'. Souza et al. (2008) avaliaram a distribuição do sistema radicular do 'Cravo' sob laranjeira 'Hamlin' em três solos de tabuleiro costeiro no Estado da Bahia. No Argissolo Amarelo e no Latossolo Amarelo argissólico, ambos caracterizados por horizontes coesos que dificultam o aprofundamento das raízes, a profundidade efetiva 
variou de 0,59 a $0,73 \mathrm{~m}$. No Argissolo Acinzentado, sem horizonte coeso, a profundidade efetiva determinada foi de $0,80 \mathrm{~m}$.

No 'Rugoso da África' foram observados valores de $0,53 \mathrm{~m}$ na linha e $0,44 \mathrm{~m}$ na entrelinha relativos à profundidade efetiva (Tabela 3). A 'Cleópatra' apresentou resultados semelhantes de profundidade efetiva em ambos os sentidos avaliados, com valores em torno de $0,35 \mathrm{~m}$. Neves et al. (2008), ao estudarem o sistema radicular de quatro portaenxertos sob copa de 'Poncã', em um Latossolo Vermelho distroférrico no Norte do Paraná, caracterizado pelo clima subtropical, observaram valores superiores aos mensurados neste trabalho, tanto para o 'Rugoso da África' como para a 'Cleópatra'. Naquelas condições as profundidades efetivas destes porta-enxertos variaram de 0,41 a $0,74 \mathrm{~m}$.

Para o porta-enxerto 'Trifoliata' os dados relativos à profundidade efetiva variaram de $0,23 \mathrm{~m}$ na linha de plantio a $0,33 \mathrm{~m}$ na entrelinha (Tabela 3 ). Abreu e Salviano (2007), no Piauí, observaram que 94,3\% das raízes do porta-enxerto 'Trifoliata' sob 'Tahiti' estavam concentradas nos primeiros 0,4 m. Em um Latossolo Vermelho distroférrico no Norte do Paraná, estudando o comportamento radicular da mesma combinação copa/porta-enxerto, Neves et al. (2004) observaram valores de profundidade efetiva de 0,53 $\mathrm{m}$ na linha e $0,67 \mathrm{~m}$ na entrelinha.

Quanto à distância efetiva, o 'Cravo' apresentou de $1,58 \mathrm{~m}$ na linha de plantio até $1,65 \mathrm{~m}$ na entrelinha (Tabela 3), resultados próximos dos de Bordin et al. (2005), ao estudarem o sistema radicular do 'Cravo' sob laranjeira 'Pêra' em um Latossolo argiloso. Por outro lado, os resultados do presente trabalho são inferiores aos obtidos por Souza et al. (2008), ao avaliarem a distribuição do sistema radicular do 'Cravo' sob a 'Hamlin' em diferentes solos no Estado da Bahia e aos obtidos Neves et al. (2004), ao avaliarem o comportamento radicular de seis portaenxertos sob 'Tahiti' em um Latossolo Vermelho distroférrico no Norte do Paraná.
Os dados relativos às distâncias efetivas variaram de $1,07 \mathrm{~m}$ na linha a $1,90 \mathrm{~m}$ na entrelinha para o 'Rugoso da África' e de 1,29 m na linha a 2,28 m na entrelinha para a 'Cleópatra' (Tabela 3). Os valores de distância efetiva observados no porta-enxerto 'Trifoliata' foram de 1,64 m na linha e 1,55 m na entrelinha (Tabela 3), inferiores aos encontrados por Neves et al. (2004) na combinação 'Trifoliata'/'Tahiti'. Essas diferenças podem ser explicadas pelo espaçamento de plantio utilizado em função das diferentes espécies de copa. A lima ácida 'Tahiti', por ter um grande desenvolvimento vegetativo, necessita de maior área do que as laranjeiras em geral, o que propicia também um maior volume de solo livre para o desenvolvimento das raízes.

As raízes do 'Cravo', 'Cleópatra' e 'Trifoliata' seguiram a tendência observada por Neves et al. (2004, 2008). Nesses trabalhos a profundidade efetiva na entrelinha foi superior à profundidade efetiva na linha, indicando um maior aprofundamento do sistema radicular na região mais exposta ao sol, e, portanto mais exposta ao dessecamento, quando comparada com a linha de plantio, que fica abrigada na sombra das plantas e provavelmente com maior quantidade de água armazenada na superfície do solo. Além disso, na região da linha de plantio existe menor competição com plantas invasoras e maior concentração de adubos, o que também pode explicar a menor necessidade de aprofundamento das raízes.

Observou-se ainda que as distâncias efetivas na entrelinha da 'Cleópatra' e do 'Trifoliata' atingiram valores muito próximos aos do raio da copa (Tabela 3 ), indicando uma maior concentração de raízes sob a copa. Machado e Coelho (2000), em 'Cravo' sob 'Tahiti', e Neves et al. (2004), em diversos porta-enxertos, também sob 'Tahiti', observaram o mesmo. Estes resultados estão de acordo com a recomendação do Grupo Paulista de Adubação e Calagem para Citros (1994), que indica adubação em faixa de largura igual ao raio da copa, sendo $2 / 3$ dentro da projeção da copa e $1 / 3$ fora, para plantas cítricas a partir de três anos de idade. 


\section{Conclusões}

A tangerineira 'Cleópatra' apresenta um sistema radicular mais vigoroso do que os demais portaenxertos avaliados.

O limoeiro 'Rugoso da África' possui maior profundidade efetiva das raízes na linha de plantio.

\section{Agradecimentos}

Os autores agradecem aos Srs. Wandayr Corrêa e Wilson Schveiczrski (IAPAR) pelo apoio na coleta dos dados e aos estagiários Mariana de Souza, Jéssica Amaral, Luiz Barizon, Wellington Borges e Tatiane Lobak pelo processamento das amostras.

\section{Referências}

ABREU, F. L. G.; SALVIANO, A. A. C. Sistema radicular de três porta-enxertos para lima ácida "Tahiti" no estado do Piauí. Semina: Ciências Agrárias, Londrina, v. 28, n. 2, p. 187-194, 2007.

BHERING, S. B. Mapa de solos do Estado do Paraná. Rio de Janeiro: Embrapa Solos, 2007. (Documentos / Embrapa Solos).

BÖHM, W. Methods of studying root systems. Berlin: Springer-Verlag, 1979. 188 p.

BONI, G.; COSTA, A. G.; GONDIM, R. S.; MONTENEGRO, A. A. T.; OLIVEIRA, V. H. Distribuição do sistema radicular do cajueiro-anão precoce (clone CCP-09) em cultivo irrigado e sequeiro, Ceará, Brasil. Revista Ciência Agronômica, Fortaleza, v. 39, n. 1, p. 1-6, 2008.

BORDIN, I.; NEVES, C. S. V. J.; AIDA, F. T.; SOUZA, W. R.; DAVOGLIO JUNIOR, A. C.; FURLANETO, T. L. R.; TAVARES FILHO, J. Sistema radicular de plantas cítricas e atributos físicos do solo em um Latossolo argiloso submetido à escarificação. Ciência Rural, Santa Maria, v. 35, n. 4, p. 820-825, 2005.

CAVIGLIONE, J. H.; KIIHL, L. R. B.; CARAMORI, P. H.; OlIVEIRA, D. Cartas climáticas do Paraná. Londrina : IAPAR, 2000. CD-ROM.

CINTRA, F. L. D.; LIBARDI, P. L.; JORGE, L. A. C. Distribuição do sistema radicular de porta-enxertos de citros em ecossistema de tabuleiro costeiro. Revista Brasileira de Fruticultura, Jaboticabal, v. 21, n. 3, p. 313-317, 1999.
COELHO, E. F.; OLIVEIRA, F. C.; ARAÚJO, E. C. E.; VASCONCELOS, L. F. L. Distribuição de raízes de laranja "Pêra" sob sequeiro e irrigação por microaspersão em solo arenoso. Pesquisa Agropecuária Brasileira, Brasília, v. 37, n. 5, p. 603-611, 2002.

CRUZ, A. C. R.; LIBARDI, P. L.; CARVALHO, L. A.; ROCHA, G. C. Balanço de água no volume de solo explorado pelo sistema radicular de uma planta de citros. Revista Brasileira de Ciência do Solo, Viçosa, v. 29, p. 1-10, 2005.

GRUPO PAULISTA DE ADUBAÇÃO E CALAGEM PARA CITROS. Recomendações de adubação e calagem para citros no estado de São Paulo. 3. ed. Cordeirópolis, 1994. Edição especial.

INSTITUTO AGRONÔMICO DO PARANÁ - IAPAR. A citricultura no Paraná. Londrina: IAPAR, 1992. 288 p. (Circular, 72).

INSTITUTO BRASILEIRO DE GEOGRAFIA E ESTATÍSTICA-IBGE.Produçãoagrícolamunicipal-2010. Disponível em: <http://www.sidra.ibge.gov.br/bda/ tabela/protabl.asp? $=1613 \& \mathrm{z}=\mathrm{t} \& \mathrm{o}=11 \& \mathrm{i}=\mathrm{P}>$. Acesso em: 30 jan. 2012.

KLAR, A. E. Irrigação: freqüência e quantidade de aplicação. São Paulo: Nobel, 1991. 156 p.

LEDO, A. da S.; LEDO, F. J. da S.; RITZINGER, R.; SOBRINHO, A. P. da C. Porta-enxertos para laranjeirasdoces (Citrus sinensis (1.) Osb.), em Rio Branco, Acre. Pesquisa Agropecuária Brasileira, Brasília, v. 34, n. 7, p. 1211-1216, 1999.

MACHADO, C. C.; COELHO, R. D. Estudo da distribuição espacial do sistema radicular do limão "Cravo" enxertado com lima ácida "Tahiti". Laranja, Cordeirópolis, v. 21, n. 2, p. 359-380, 2000.

MAZZA, J. A.; VITTI, G. C.; PEREIRA, H. S.; MENEZES, G. M.; TAGLIARINI, C. H. Influência da compactação no desenvolvimento do sistema radicular de citros: sugestão de método qualitativo de avaliação e recomendação de manejos. Laranja, Cordeirópolis, v. 15, n. 2, p. 251-262, 1994.

MÜLLER, G. W.; NEGRI, J. D.; AGUILAR-VILDOSO, C. I.; MATTOS JÚNIOR, D.; POMPEU JÚNIOR, J.; TEÓFILO SOBRINHO, J.; CARVALHO, S. A.; GIROTTO, L. F.; MACHADO, A. A. Morte súbita dos citros: uma nova doença na citricultura brasileira. Laranja, Cordeirópolis, v. 23, n. 2, p. 371-386, 2002.

NEVES, C. S. V. J.; MURATA, I. M.; STENZEL, N. M. C.; MEDINA, C. C.; BORGES, A. V.; OKUMOTO, S. H.; LEE, R. H. C.; KANAI, H. T. Root distribution of rootstocks for "Tahiti" lime. Scientia Agricola, Piracicaba, v. 61, n. 1, p. 94-99, 2004. 
NEVES, C. S. V. J.; STENZEL, N. M. C.; CARVALHO, S. L. C.; FURLANETO, T. L. R.; OKUMOTO, S. H. Sistema radicular de quatro porta-enxertos sob copa de tangerina "Poncã". Ciência e Agrotecnologia, Lavras, v. 32, n. 2, p. 487-492, 2008.

OLIVEIRA, L. F. C.; VIEIRA, D. B.; SOUZA, I. S. Estudo do sistema radicular da tangerina "Cleópatra" com copa de laranjeira "Pêra". Laranja, Cordeirópolis, v. 19, n. 1, p. 117-131, 1998.

POMPEU JÚNIOR, J. Porta-enxertos para citros. In: RODRIGUEZ, O.; VIÉGAS, F. C. P.; POMPEU JÚNIOR, J.; AMARO, A. A. Citricultura brasileira. 2. ed. Campinas: Fundação Cargill, 1991. p. 265-280.

PRUDENTE, R. M.; SILVA, L. M. S. da; SOBRINHO, A. P. da C. Comportamento da laranjeira 'Pêra' sobre cinco porta-enxertos em ecossistema de tabuleiros costeiros, Umbaúba-SE. Revista Brasileira de Fruticultura, Jaboticabal, v. 26, n. 1, p. 110-112, 2004.

SOUZA, L. S.; SOUZA, L. D.; PAIVA, A. Q.; RODRIGUES, A. C. V.; RIBEIRO, L. S. Distribuição do sistema radicular de citros em uma topossequência de solos de tabuleiro costeiro do Estado da Bahia. Revista Brasileira de Ciência do Solo, Viçosa, v. 32, p. 503-513, 2008.

STENZEL, N. M. C.; NEVES, C. S. V. J. Rootstocks for 'Tahiti' lime. Scientia Agricola, Piracicaba, v. 61, n. 2, p. 151-155, 2004.
STENZEL, N. M. C.; NEVES, C. S. V. J.; GOMES, J. C.; MEDINA, C. C. Performance of 'Ponkan' mandarin on seven rootstocks. Hortscience, Ames, v. 38, n. 2, p. 176-178, 2003.

STENZEL, N. M. C.; NEVES, C. S. V. J.; GONZALEZ, M. G. N.; SCHOLZ, M. B. dos S.; GOMES, J. C. Desenvolvimento vegetativo, produção e qualidade dos frutos da laranjeira 'Folha Murcha' sobre seis portaenxertos no Norte do Paraná. Ciência Rural, Santa Maria, v. 35, n. 6, p. 1281-1286, 2005c.

STENZEL, N. M. C.; NEVES, C. S. V. J.; MARUR, C. J.; GOMES, J. C. Crescimento vegetativo de plantas cítricas no norte e noroeste do Paraná. Revista Brasileira de Fruticultura, Jaboticabal, v. 27, n. 3, p. 412-417, 2005 b.

STENZEL, N. M. C.; NEVES, C. S. V. J.; SCHOLZ, M. B. S.; GOMES, J. C. Comportamento da laranjeira "Folha Murcha" em sete porta-enxertos no noroeste do Paraná. Revista Brasileira de Fruticultura, Jaboticabal, v. 27, n. 3, p. 408-411, 2005a.

STUCHI, E. S.; DONADIO, L. C. Laranjeira folhamurcha. Jaboticabal: Funep, 2000.

STUCHI, E. S.; ESPINOZA-NÚÑEZ, E.; MOURÃO FILHO, F.A.A.; ORTEGA, E. M. M. Vigor, produtividade e qualidade de frutos de quatro tangerineiras e híbridos sobre quatro porta-enxertos. Revista Brasileira de Fruticultura, Jaboticabal, v. 30, n. 3, p. 741-747, 2008. 
